\title{
Introdução: A Análise de Discurso Crítica
}

(Introduction: Critical Discourse Analysis)

\author{
Izabel MagalHÃES \\ (Universidade de Brasília)
}

ABSTRACT: This is a brief introduction to critical discourse analysis (CDA), viewing $C D A$ as both a continuation of critical linguistics (CL), practised in the United Kingdom in the 1970s, as well as an international transdisciplinary field derived from linguistics, with an interest in text and in power relations.

KEY-WORDs: Critical Discourse Analysis; Critical Linguistics; Power; Social Change.

RESUMO: Esta é uma breve introdução à análise de discurso crítica (ADC), considerando a ADC tanto uma continuação da lingüística crítica $(L C)$, praticada na Grã-Bretanha na década de 1970, como também um campo transdisciplinar internacional derivado da lingüística, com interesse no texto e nas relações de poder.

Palavras-Chave: Análise de Discurso Crítica; Linguiústica Crítica; Poder; Mudança Social.

Há quase duas décadas, publiquei um artigo na revista D.E.L.T.A., com o título "Por uma Abordagem Crítica e Explanatória do Discurso" (Magalhães 1986). Desde essa época, venho contribuindo para o desenvolvimento dessa abordagem de estudo da linguagem no Brasil e, particularmente, no Grupo de Pesquisa de Linguagem e Ideologia da Universidade de Brasília. Atualmente, é uma área de estudo consolidada, com pesquisas já realizadas e outras em andamento, em diversas instituições nacionais. ${ }^{1}$

Um rápido esclarecimento com relação à tradução do termo inglês critical discourse analysis. Embora exista a expressão portuguesa 'análise

\footnotetext{
1 Este texto está baseado em parte de um capítulo que escrevi para um livro organizado por L. Berardi, da Universidade do Chile (Magalhães, 2003).
} 
crítica do discurso', por exemplo no livro organizado por E. Pedro (1997), prefiro o termo 'análise de discurso crítica'. Não se trata de mera questiúncula terminológica. Há uma razão para isso: no Brasil, a tradição de estudo do discurso é forte. Só para ilustrar esse ponto, o livro de E. Orlandi $A$ Linguagem e Seu Funcionamento foi publicado em 1983 ( $1^{\text {a }}$ ed.). Essa tradição acadêmica se consolidou no Brasil com a expressão análise de discurso (Orlandi, 1999).

A análise de discurso tem como propósito o debate teórico e metodológico do discurso: a linguagem como prática social. Nesse sentido, a análise de discurso, seja qual for a sua orientação, se opõe à lingüística formal (Neves 1997).

Nesta introdução, pretendo situar a análise de discurso crítica no contexto internacional, no qual ela é hoje uma disciplina de destaque pelas contribuições que vem oferecendo para a compreensão de alguns dilemas contemporâneos. Esses dilemas são debatidos principalmente em três periódicos internacionais: Discourse and Society, Cadernos de Linguagem e Sociedade (Papers on Language and Society) e, mais recentemente, Critical Discourse Studies.

Os artigos deste número especial de D.E.L.T.A. foram escritos em 2002 e 2003 . O propósito é oferecer uma visão ampla da ADC, conforme a orientação de diversos pesquisadores no Brasil e no exterior. Inicialmente, farei um comentário sobre o percurso da análise de discurso crítica e, em seguida, discutirei a pergunta: Por quê crítica?

Na década de 1970, na Universidade de East Anglia, Grã-Bretanha, um grupo de pesquisadores desenvolveu uma abordagem de estudo da linguagem conhecida como lingüística crítica (LC). Em 1979, Fowler, Kress, Hodge, e Trew publicaram Language and Control (Linguagem e Controle), um livro que teve repercussão entre lingüistas e pesquisadores da linguagem que se interessavam pela relação entre o estudo do texto e os conceitos de poder e ideologia.

$\mathrm{Na}$ década de 1980, outros estudiosos se dedicaram ao desenvolvimento dessa abordagem. Fairclough, na Universidade de Lancaster, usou a expressão 'análise de discurso crítica' pela primeira vez em artigo seminal no Journal of Pragmatics (Fairclough, 1985). A análise de discurso crítica (ADC) pode ser considerada uma continuação da lingüística crítica (Wodak, 2001). 
Não obstante, considerar a ADC como uma continuação da LC é uma redução de questões fundamentais que foram explicitadas pela ADC, tanto em termos teóricos como metodológicos. A ADC estuda textos e eventos em diversas práticas sociais, propondo uma teoria e um método para descrever, interpretar e explicar a linguagem no contexto sociohistórico. Enquanto a LC desenvolveu um método para analisar uma pequena amostra de textos, a ADC desenvolveu o estudo da linguagem como prática social, com vistas à investigação de transformações na vida social contemporânea (Fowler 1996; Fairclough 2001). A ADC oferece uma valiosa contribuição de lingüistas para o debate de questões ligadas ao racismo, à discriminação baseada no sexo, ao controle e à manipulação institucional, à violência, à identidade nacional, à auto-identidade e à identidade de gênero, à exclusão social.

A ADC é, como já indiquei, um campo disciplinar reconhecido internacionalmente pelo trabalho sistemático de diversos estudiosos: Fairclough, numa série de obras (Fairclough 1989, 1992, 1995a, 1995b, 2000, 2003); Wodak 1996; Chouliaraki e Fairclough 1999; van Dijk 1985, 1986, 1998. A contribuição principal de Fairclough foi a criação de um método para o estudo do discurso e seu esforço extraordinário para explicar por que cientistas sociais e estudiosos da mídia precisam dos lingüistas (Fairclough 1989, 2001; Chouliaraki e Fairclough 1999).

Segundo Chouliaraki e Fairclough, a ADC está situada na ciência social crítica e na pesquisa crítica sobre a mudança social na sociedade moderna posterior (1999: 1). O termo 'modernidade posterior' é usado por Giddens (1991), com referência às transformações econômicas e socioculturais das três últimas décadas do século XX, em que os avanços na tecnologia da informação e na mídia apartaram os signos de sua localização específica, permitindo sua livre circulação nos limites temporais e espaciais. Chouliaraki e Fairclough argumentam que "a ADC deveria ser considerada como uma contribuição ao campo da pesquisa crítica sobre a modernidade posterior" (1999: 3). Ao comentarem as profundas mutações econômicas e socioculturais das últimas décadas, Chouliaraki e Fairclough sugerem que tais transformações resultam em parte das estratégias de grupos particulares em um 'sistema particular'. De acordo com esses autores, "há uma necessidade urgente de teorização e de análise críticas da modernidade posterior que possam não apenas iluminar o novo mundo que está 
emergindo, mas também indicar as direções alternativas não realizadas existentes" (1999: 4).

Van Dijk tem contribuído para o debate da ADC como organizador de Discourse and Society, um periódico internacional de peso na área. Grande parte do reconhecimento da ADC como tradição acadêmica se deve à estimulante discussão que se faz nesse periódico desde 1990. Além de Handbook of Discourse Analysis (1985), van Dijk publicou sobre o discurso da mídia (1986), e sobre racismo e ideologia (1998).

Wodak faz uma reflexão sobre até que ponto os estudiosos engajados na análise lingüística, semiótica e discursiva, com diferentes olhares, "partilham uma perspectiva particular em que os conceitos de poder, ideologia e história são centrais." (Wodak 2001: 7)

Uma coletânea da ADC que recebeu muita atenção foi Texts and Practices, organizada por Caldas-Coulthard e Coulthard (1996). Uma excelente coletânea recente, organizada por Wodak e Meyer (2001), é Methods of Critical Discourse Analysis. Uma outra discussão sobre a ADC como teoria e método é a coletânea organizada por Jaworski e Coupland (1999), The Discourse Reader. Destaco, nessa obra, a inclusão de textos clássicos de autores que, embora não pratiquem a análise de discurso, apresentam contribuições relevantes para esse campo transdisciplinar. Um dos capítulos é nada mais, nada menos do que o famoso texto de Bakhtin sobre os gêneros discursivos ("The Problem of Speech Genres").

Com relação à transdisciplinaridade da ADC, Chouliaraki e Fairclough lembram o seguinte:

Vemos a ADC trazendo uma variedade de teorias ao diálogo, especialmente teorias sociais, por um lado, e teorias lingüísticas, por outro, de forma que a teoria da ADC é uma síntese mutante de outras teorias; não obstante, o que ela própria teoriza em particular é a mediação entre o social e o lingüístico - a 'ordem do discurso', a estruturação social do hibridismo semiótico (interdiscursividade). (1999: 16)²

Trata-se, portanto, de uma transdisciplinaridade com um foco específico sobre a relação entre o mundo social e a linguagem. Qual é a natureza dessa relação? Certamente a linguagem não é meramente o reflexo da

2 Todas as traduções desta Introdução são de minha autoria. 
vida social, o que significaria um lugar para a sociedade e um outro para a linguagem (Magalhães 2000).

Essa metáfora da sociolingüística é redutora da força construtiva da linguagem como discurso, de acordo com Foucault (1987). Ao contrário, a ADC afirma que o lingüístico é social (Kress 1989). Essa afirmação está contida na definição de Fairclough (2001), de discurso como forma de ação e como forma de representação. Isso significa dizer que agimos discursivamente, como também representamos discursivamente o mundo (social) a nossa volta.

Por quê crítica? O aspecto crítico da ADC tem suscitado questões, principalmente os artigos de Widdowson (por exemplo, Widdowson 2000). Nesse trabalho, Widdowson faz uma crítica à ADC, com base na seguinte afirmação de Caldas-Coulthard e Coulthard (1996: xi):

A análise de discurso crítica é essencialmente política em seu propósito com seus praticantes agindo sobre o mundo para transformá-lo e com isso contribuir para criar um mundo no qual as pessoas não sejam discriminadas devido a sexo, credo, idade ou classe social.

O argumento de Widdowson contra a ADC está na seguinte citação:

Este é um projeto ambicioso, e certamente muito além dos modestos objetivos do meu próprio trabalho na análise crítica. Eu não tive nenhum compromisso com uma causa: meu propósito não foi expor, mas explicar; não foi descobrir um propósito sinuoso, mas tentar entender o que havia nos textos que resultava em determinadas interpretações...Na verdade, na perspectiva da ADC, eu não estava realmente fazendo análise de discurso, pois o discurso só pode significar um conjunto de valores socialmente construídos, que implicam inevitavelmente a ideologia (Widdowson 2000: 155-156).

A crítica de Widdowson traz uma questão: é possível a neutralidade? De fato, a motivação de Widdowson é política, no sentido de que não há ciência neutra como queriam os positivistas (Rajagopalan 2001/02; 2003). A distinção tradicional entre ciência e ideologia é rejeitada por teóricos como Foucault, que dedica um capítulo a essa questão em sua obra $A$ Arqueologia do Saber (1987).

Em um seminário sobre poder, ética e validade, organizado por mim e por S. Gieve na Universidade de Lancaster, Grã-Bretanha, em 1994, fo- 
ram debatidas amplamente as mudanças ocorridas nas últimas décadas nos paradigmas da pesquisa na área de estudos da linguagem. Um ponto central dos debates foi a constatação de que em diversas situações de pesquisa os sujeitos pesquisados muitas vezes aceitam as imposições feitas a eles/elas pelo simples fato de que pode ser difícil não aceitá-las (Magalhães e Gieve 1994: v).

Nesse seminário, Fairclough destacou os diferentes sentidos atribuídos ao termo 'poder' (Fairclough 1989). Existe o poder físico, de uma pessoa sobre outra, por exemplo, na relação entre homens e mulheres, em que os homens freqüentemente tiram partido da força física para ameaçar e mesmo matar mulheres (Rorty 1996; Suárez e Bandeira, orgs., 1999). Tais atos de poder geralmente co-ocorrem em uma sociedade particular com a dominação simbólica, como por exemplo, na linguagem discriminatória (sexista ou racista) e na representação visual (Magalhães 1995, 2002).

No discurso médico, na área de pediatria, as mães das crianças geralmente são representadas como 'inadequadas' porque são consideradas exclusivamente como responsáveis por alimentar e cuidar dos filhos. Por essa razão, há evidências de manipulação ideológica das mulheres por parte dos médicos, para seguirem suas recomendações sem qualquer questionamento (Magalhães 2000).

Como sugere Foucault (1980: 98), o poder é organizado como uma rede, na qual os sujeitos participam como 'alvos que consentem' e, ao mesmo tempo, como 'elementos de sua articulação'. Foucault tem interesse nas manifestações de poder em práticas de vigilância ou de controle nas prisões, nas escolas e nos hospitais. Essas práticas também operam na definição da loucura e da sexualidade (Foucault 1985). Um aspecto negligenciado da obra de Foucault é a visão de que o poder não é apenas uma estratégia descendente, pois "não há relações de poder sem resistências" (1980: 142). Portanto, conforme Fairclough (2001), é preciso considerar o poder em sua dialética: como local de poder e como afirmação de poder. É devido a essa dialética que a ADC deve ser reflexiva em sua postura institucional, pois a "teoria é ela própria uma prática" (Chouliaraki e Fairclough 1999: 29).

Como registrei nos parágrafos anteriores, a dimensão crítica relaciona a ADC com uma preocupação explícita com o exercício do poder nas relações sociais, o que inclui as relações de gênero e classe social, como tam- 
bém as relações entre as raças e as etnias. A ADC atualmente se refere à abordagem da lingüística adotada por estudiosos que tomam o texto como unidade básica do discurso e da comunicação e que se voltam para a análise das relações de luta e conflito social (Wodak 2001: 2).

O estudo das representações dessas relações nos textos distingue a ADC de outras tradições acadêmicas, como a sociolingüística variacionista, a lingüística textual, a análise da conversação e a pragmática (Fairclough 1989, 2001). Isso não significa, porém, que essas tradições de estudo sejam homogêneas, uma vez que alguns trabalhos realizados aqui podem adotar uma perspectiva crítica.

Uma palavra final sobre o processo de seleção dos autores incluídos neste número especial. O contato inicial foi feito com 16 pesquisadores, no Brasil e no exterior, todos praticantes da ADC. O que se segue é produto de um trabalho de dois anos.

E-mail:mizabel@unb.br

\section{REFERÊNCIAS BibLIOGRÁFICAS}

Bakhtin, M. 1999. The Problem of Speech Genres. In: A. Jaworski e N. Coupland (orgs.), pp. 121-132.

Caldas-Coulthard, C. R. e M. Coulthard (orgs.) 1996. Texts and Practices: Readings in $C D A$. Londres e Nova York: Routledge.

Chouliaraki, L. e N. Fairclough. 1999. Discourse in Late Modernity: Retbinking Critical Discourse Analysis. Edimburgo: Edinburgh University Press.

Van Dijk, T. A. (org.) 1985. Handbook of Discourse Analysis. 4 vols. Nova York: Academic Press.

. 1986. Racism in the Press. Londres: Edward Arnold.

. 1998. Ideology: A Multidisciplinary Approach. Londres: Sage.

Fairclough, N. 1985. Critical and Descriptive Goals in Discourse Analysis. Journal of Pragmatics, 9: 739-63.

1989. Language and Power. Londres e Nova York: Longman. 1992. Discourse and Social Change. Cambridge: Polity Press. . 1995a. Critical Discourse Analysis. Londres e Nova York: Longman. . 1995b. Media Discourse. Oxford: Edward Arnold. 
. 2000. New Labour, New Language. Londres e Nova York: Routledge.

. 2001. Discurso e Mudança Social. Coord. e pref. à ed. bras. I. Magalhães. Trad. I. Magalhães et al. Brasília, DF: Editora Universidade de Brasília.

. 2003. Analysing Discourse: Textual Analysis for Social Research. Londres e Nova York: Routledge.

Foucault, M. 1980. Power/Knowledge. Org. C. Gordon. Nova York: Harvester Wheatsheaf.

. 1985. História da Sexualidade (Histoire de la Sexualité). Vol. I.

$6^{a}$ ed. Trad. M. T. Albuquerque e J. A. Albuquerque. Rio de Janeiro: Edições Graal.

. 1987. A Arqueologia do Saber (L’Archéologie du Savoir). $3^{\mathrm{a}}$ ed. Trad.

L. F. Neves. Rio de Janeiro: Forense-Universitária.

Fowler, R. 1996. On Critical Linguistics. In: C. R. Caldas-Coulthard e M. Coulthard (orgs.) : 3-14.

, B. Hodge, G. Kress, e T. Trew. 1979. Language and Control. Londres, Boston e Henley: Routledge \& Kegan Paul.

Giddens, A. 1991. Modernity and Self-Identity: Self and Society in the Late Modern Age. Cambridge: Polity Press.

Jaworski, A. e N. Coupland (orgs.) 1999. The Discourse Reader. Londres e Nova York: Routledge.

KRess, G. 1989. Linguistic Processes in Sociocultural Practice. Oxford: Oxford University Press.

Magalhães, I. 1986. Por Uma Abordagem Crítica e Explanatória do Discurso. D.E.L.T.A., 2 (2): 181-205.

. 1995. A Critical Discourse Analysis of Gender Relations in Brazil. Journal of Pragmatics, 23: 183-97.

. 2000. Eu e Tu: A Constituição do Sujeito no Discurso Médico. Brasília, DF: Thesaurus.

. 2002. The Technologisation of Discourse and the Semiotic Construction of Gender Identity. II International Conference on Gender and Language/Igala. Universidade de Lancaster, Grã-Bretanha.

. 2003. Critical Discourse Analysis and Gender Ideology in the Brazilian Constitution. In: L. Berardi (org.). Análisis Crítico del Discurso: Perspectivas Latinoamericanas. Santiago, Chile: Frasis Editores : 17-50. e S. Gieve. 1994. Introduction. In: S. Gieve e I. Magalhães (orgs.) Power, Ethics and Validity: The Relationship Between Researcher and Researched. CRILE Occasional Paper, 6. Universidade de Lancaster, Grã-Bretanha. 
Neves, M. H. 1997. A Gramática Funcional. São Paulo: Martins Fontes.

Orlandi, E. 1983. A Linguagem e Seu Funcionamento. $1^{a}$ ed. São Paulo: Brasiliense. . 1999. Análise de Discurso. Campinas, SP: Pontes.

Pedro, M. E. (org.) 1997. Análise Crítica do Discurso. Lisboa: Editorial Caminho.

Rajagopalan, K. 2001/02. Editorial. Cadernos de Linguagem e Sociedade (Papers on Language and Society), 5: 5-8.

. 2003. Por Uma Lingïística Crítica: Linguagem, Identidade e a Questão Ética. São Paulo: Parábola Editorial.

Rorty, R. 1996. Feminismo, Ideologia e Desconstrução: Uma Visão Pragmática. In: S. ŽǏ̌EK (org.) : 227-34.

Sarangi, S. e M. Coulthard (orgs.) 2000. Discourse and Social Life. Harlow: Pearson Education/Longman.

SuÁrez, M. e L. BandeIRA (orgs.) 1999. Violência, Gênero e Crime no Distrito Federal. Brasília, DF: Paralelo 15; Editora Universidade de Brasília.

Widdowson, H. 2000. Critical Practices: On Representation and the Interpretation of Text.. In: S. Sarangi e M. Coulthard (orgs.) : 155-69. Wodak, R. 1996. Disorders of Discourse. Londres e Nova York: Longman. . 2001. What CDA is About - A Summary of Its History, Important Concepts and Its Developments. In: R. Wodak e M. Meyer (orgs.) $: 1-13$.

e M. Meyer (orgs.) 2001. Methods of Critical Discourse Analysis. Londres, Thousand Oaks, Nova Delhi: Sage Publications.

Žı̌̌EK, S. (org.) 1996. Um Mapa da Ideologia. Trad. V. Ribeiro. Rio de Janeiro: Contraponto. 